\title{
ATENDENTE DE ENFERMAGEM: POR QUÊ? ATÉ QUANDO?
}

NURSING ATTENDANT: WHY? HOW LONG?

ATENDIENTE DE ENFERMERÍA PORQUÉ ? - HASTA CUANDO?

\section{Marília Martins Bezerra ${ }^{1}$ Débora Rodrigues Guerra Maria Vilani Cavalcante Guedes ${ }^{2}$}

RESUMO: A qualificação dos profissionais de enfermagem é importante, pois estes lidam com vidas que necessitam de assistencia qualificada. Este estudo objetiva analisar opiniões de profissionais da área de saúde sobre atendentes de enfermagem. Realizado no período de março a julho de 1997, foram entrevistados enfermeiros, médicos, auxiliares e técnicos de enfermagem de hospitais públicos e filantrópico de Fortaleza - CE. Os resultados mostraram: os entrevistados percebem que os atendentes, muitas vezes, desempenham o mesmo que os auxiliares de enfermagem, podendo interferir na qualidade do serviço prestado e causar iatrogenias; outros os consideram importantes nas instituiçōes visto a prática; alguns se mostram completamente contra o processo de profissionalização dos trabalhadores não-qualificados; outros se colocam a favor, mas discordam do modo como vem ocorrendo, pois não percebem mudança na postura profissional após serem qualificados. Entende-se que esta questão é merecedora de atitudes imediatas, pois está relacionada com o objeto principal da enfermagem: o cuidar.

UNITERMOS: Qualificação profissional - Recursos humanos - Atendentes de enfermagem.

ABSTRACT: Qualificatin for nursing professionals is important for they deal with lives that need qualified care. This study aims at analysing health profesionals opinions about nursing attendants. It was accomplished between March and July, 1997. Nurses, physicians, nursing aids and technicians at public and philantropic hospitals in Fortaleza - CE were intervied. The outcomes show that nursing attendants. most times, perform the same procedures as the nursing aids and may interfere with the provided service quality and cause iatrogenies; others consider them as important at institutions for their practice; some others express themselves completely against the non-qualified profissionalisation process; anothers express themselves for this process, but disaggree on how it is accomplished for they do not perceive any change in their professional profile after being qualified. We do understand that this question is deserving of immediate attitudes for it is related to nursing principal subject: Caring.

KEYWORDS: Professional qualification - Human resources - Nursing attendant.

\footnotetext{
${ }^{1}$ Discentes da Graduação em Enfermagem da Universidade Estadual do Ceará e Bolsistas do Programa Especial de Treinamento - PET/CAPES.

2 Docente da Graduação em Enfermagem da Universidade Estadual do Ceará e Tutora do Programa Especial de Treinamento - PET/CAPES.
}

R. Bras. Enferm. Brasília, v. 51, n. 1, p. 77-92, jan./mar., 1998 
RESUMEN: La calificación de los profesionales de enfermeria es importante, pués éstes tratan con vidas que necesitan de asistencia calificada. Este estudio objetiva analizar opiniones de profesionales de la área de salud sobre atendientes de enfermeria. Realizado en el transcurso de marzo a julio de 1997, fueron entrevistados enfermeros, médicos, auxiliares y técnicos de enfermeria de hospitales públicos y filantrópicos de Fortaleza - CE. Los resultados mostraron: Ios entrevistados se dan cuenta que los atendientes, muchas veces, desempeñan lo mismo que los auxiliares de enfermeria, podiendo interferir en la calidad del servicio prestado y causar iatrogenias; otros los consideran importantes en las instituciones por lo visto en la práctica; algunos se muestran completamente contra el proceso de profesionalización de los trabajadores no calificados; otros se colocan a favor, pero discordan del modo como vienen ocurriendo, pues no notan cambios en la postura profesional después de ser calificados. Entiendese que esta cuestión es merecedora de actitudes inmediatas, pues está relacionada com el objeto principal de la enfermeria: el cuidar.

UNITÉRMINOS: Calificación profesional - Recursos humanos - Atendientes de enfermeria.

\section{INTRODUÇÃO}

O mundo moderno exige dos profissionais participação ativa e eficiência na execução de suas atividades peculiares. Para se executar uma atividade em qualquer área do conhecimento, faz-se necessário qualificação adequada.

A atualização torna-se indispensável a cada dia, explorando do profissional sempre o máximo de seu potencial. O saber deve ser geral, porém respaldado em um bom nível de conhecimento nas diversas áreas, uma delas é a saúde que exige integração de diversas ciências como a Biologia, a Anatomia, a Fisiologia, a Antropologia, a Sociologia, a Psicologia, entre outras.

A qualificação dos profissionais da saúde, especialmente da enfermagem, é essencial, pois estes lidam com seres humanos, vidas que necessitam receber atenção e assistência de qualidade. Isto exige subsídio em conhecimentos que assegurem bons resultados $e$, conseqüentemente, o reconhecimento de sua clientela. Portanto, não é justo que esta seja assistida por trabalhadores sem qualificação.

Deste modo, o indivíduo que procura o serviço de saúde, por ser um ambiente onde supõe-se existir pessoas capacitadas, pode ser enganado, pois ainda hoje pode encontrar, nos ambientes nosocomiais, servidores com diferentes denominações incorporados no mercado de trabalho em função da falta de auxiliares e técnicos de enfermagem (situação encontrada mais comumente no interior do país) ou principalmente como resultado do interesse dos empregadores em mantê-los como mão-de-obra de baixo custo e de fácil substituição.

É certo que a boa capacitação é condição para o exercício profissional de excelência e, no âmbito da equipe de enfermagem, devido à divisão social do trabalho, tanto enfermeiro, como o técnico e o auxiliar de enfermagem e ainda a 
parteira têm suas funçōes peculiares com amparo na Legislação de Enfermagem, isto é, têm seu trabalho fiscalizado e protegido legalmente pelos Conselhos Federal e Regionais de Enfermagem - COFEN e CORENs.

Entretanto, existem casos na Enfermagem em que trabalhadores sem qualificação realizam tarefas empiricamente, pois não receberam nenhuma formação que subsidiasse a execução de seu trabalho e executam açōes sem teoria nem técnica, ou mesmo as fazem somente porque viram, no decorrer no tempo de serviço, um outro fazer e se sentiram obrigados pela situação em realizá-las de qualquer maneira. Dentre eles, podemos destacar o ATENDENTE DE ENFERMAGEM.

Se refletirmos criticamente sobre as políticas de saúde e planos econômicos que operam no país, vemos que este ocupacional é decorrente do fracasso econômico-social.

Então, para quem não teve oportunidade de estudo, o trabalho em saúde sem qualificação é uma alternativa de emprego. Surge assim o atendente de enfermagem.

Quanto a esta questảo corroboramos como Antunes (1995: 38):

"Longe de tentar esgotá-la, pretendemos tão somente tentar entender que poder-se-á contribuir para que esta inserção se mantenha, e que prejuizos ela traz para a qualidade da assistência de enfermagem enquanto profissão e para os atendentes ou qualquer outro nome que tenham, trabalhadores sem voz, sem título, sem direitos, sem dignidade profissional, cidadania e, no entanto, responsáveis pelo primeiro lugar na produção de ações de enfermagem".

Em 1986, o então Presidente da República, José Sarney, sancionou a Lei 7.498, que limitava a atuação de atendentes até o ano de 1996, de modo que, durante uma década, procurassem profissionalizar-se através de cursos regulares de técnicos ou auxiliares de enfermagem, ou mesmo através da prova de suplência profissional. De acordo com Vieira (1992), ao encontro desta resolução, o Ministério da Saúde, em 1989, elaborou diretrizes de Política de Recursos Humanos para o Sistema Único de Saúde em que privilegia preparaçăo e administração destes, com a compreensão de que são agentes do processo de mudança; estabeleceu como uma das prioridades relativa à preparação de Recursos Humanos, a formação profissional do pessoal já engajado na rede sem qualificação específica; recomendou o ensino através da Escola Técnica para garantia de integração ensino/serviço, a utilização do trabalho como princípio pedagógico nos processos de formação; a articulação com os Conselhos de Saúde e a sensibilização das entidades profissionais para a participação no processo.

Porém, o parágrafo único do artigo 23 da referida Lei, que limitava a presença de pessoal sem formação específica nos serviços de saúde institucionalizados até 1996, foi modificado através da Lei $8.967 / 94$, sancionada pelo Presidente da República Itamar Franco. O parágrafo único do artigo 23 da Lei $7.498 / 86$, passou a vigorar com a seguinte redação: "É assegurado aos 
atendentes de enfermagem, admitidos antes da vigência desta Lei, o exercício das atividades elementares da enfermagem, observado o disposto em seu artigo 15 (COREN, 1997: 39). É lembrado que o artigo 15 da Lei 7.498/86 afirma que as atividades da enfermagem exercidas por técnicos, auxiliares ou outros servidores devem ser orientadas e supervisionadas por enfermeiro (COREN, 1997).

Contudo, os atendentes de enfermagem que não se profissionalizaram durante o período 1986-1996 continuam atuando em instituições de saúde e, até mesmo, em atendimento em domicílios, mesmo sem se enquadrarem como qualificados para o exercício profissional. Como não bastam ações puramente mecanicistas e tarefeiras, mas sim respaldadas no conhecimento que é adquirido através de uma formação profissional, esta condição leva a uma discussão na enfermagem no que se refere à necessidade de qualificação destes trabalhadores. Seus profissionais-enfermeiros, técnicos e auxiliares de enfermagem - alertaram-se para debater esta questão, na tentativa de modificarem a situação atual que interfere na qualidade da prestação de saúde à população.

A referida questão compromete o exercício profissional da enfermagem, visto que estes trabalhadores não receberam preparo formal em teoria e prática e atuam na assistência das necessidades bio-psico-sociais de pessoas que, muitas vezes, não conseguem avaliar a qualidade do trabalho a elas prestado. É uma problemática política por ser, em grande parte, responsabilidade dos governantes que, no exercício do poder, permitem o acesso e a permanência destes trabalhadores sem qualificação em serviços essenciais como o trabalho em saúde pelo fato de apresentarem menor custo salarial. Ainda evidencia-se como problema social por ser a sociedade quem paga impostos com a finalidade de receber um serviço de saúde de qualidade, porém sofre as conseqüências do trabalho realizado por pessoas não qualificadas.

Deste modo, sentimo-nos motivadas a realizar o presente estudo sobre a não qualificação profissional de ocupacionais de enfermagem investigando a opinião dos profissionais médicos, enfermeiros, técnicos e auxiliares de enfermagem, por serem os que freqüentemente convivem com estes trabalhadores sem qualificação e podem perceber a importância da capacitação, da influência e da interferência desse pessoal nas ações de saúde prestadas à clientela.

\section{OBJETIVOS}

- Analisar a opinião de profissionais da área de saúde sobre a presença de trabalhadores não qualificados na enfermagem;

- Verificar a opinião dos profissionais da saúde sobre as repercussões de trabalhadores não-qualificados nos serviços e para a sociedade;

- Conhecer a opinião dos sujeitos sobre a profissionalização do atendente de enfermagem;

- Identificar o que os profissionais sugerem para a resolução desta problemática. 


\section{ASPECTOS GERAIS DA PROBLemÁtica do ATENDENTE DE ENFERMAGEM}

A questão do atendente de enfermagem é um assunto pertinente à história da prática profissional, ligada às condições sócio-políticas e econômicas.

Fazendo-se uma retrospectiva histórica, pode-se perceber que a prática da enfermagem foi vivenciada pela mulher enquanto mãe, dona-de-casa, esposa de pajé, escrava, prostituta e irmã de caridade, vindo a se firmar como profissão no contexto capitalista, quando passa a desenvolver suas ações na instituição hospitalar.

Para Antunes (1995); p. 47):

"sem estudo e sem profissão, o mercado de trabalho em saúde apresenta-se como uma das alternativas de emprego para aquelas que não conseguem acesso à qualificação profissional. Com a herança social das cuidadoras caritativas, do trabalho feminino, submisso e obediente surgem os atendentes de enfermagem para executar as tarefas manuais, diligentes auxiliares $e$ cumpridoras das ordens médicas e sob o controle eficiente das profissionais enfermeiras".

A partir do avanço da tecnologia, com a industrialização, houve crescimento numérico de pessoas atuando na área, o que não coincidiu com a preocupação em relação à qualidade.

Assim, com a ascensão do capitalismo, o setor saúde se preocupa principalmente com o aspecto biológico dos indivíduos, pois é através deste que se obtém lucros. O sistema produtivo não estava preocupado com a qualidade dos profissionais que assistiam o ser humano e sim com o lucro que esta assistência poderia trazer. Talvez até porque o hospital, como ambiente de atendimento de saúde curativa, torna-se empresa e, como tal, visa obter benefícios em termos monetários.

Como se percebe, o desenvolvimento da enfermagem esteve diretamente relacionado ao padrão saúde desejado pelo sistema político-econômico. Quanto a esse aspecto, nos dizem Santos; Souza; Galvão (1988: 77):

“... o processo de expansão e modernização da rede de serviços de saúde no Brasil, observado nas últimas décadas, foi marcado pela adoção de políticas setoriais que privilegiaram a privatização do setor, a acentuação da dicotomia histórica entre ações curativas individuais e ações coletivas de saúde pública, a discriminação da oferta de serviçoss à população em função de sua importância relativa para o sistema econômico, a progressiva simplificação de procedimentos nos serviços públicos e a diminuição relativa de gastos".

Daí o grande contingente de pessoal não qualificado como executor da saúde para suprir as necessidades de um sistema que visava o atendimento de uma coletividade que não gerava lucros para as empresas de saúde capitalistas. 
Esta maneira de perceber as necessidades de saúde da população, onde havia grandes preocupações como esta era cuidada, favoreceu o crescimento da categoria de atendentes de enfermagem que têm contribuído para a profissão, contudo, ao mesmo tempo, têm lhe trazido dificuldades por não terem formação profissional adequada e realizarem atividades junto a clientes embora não tenham nenhum respaldo formal para ser considerado profissional de enfermagem. Compreendemos que eles continuam na área da enfermagem para executarem apenas tarefas elementares previstas na legislação da profissão.

Corroboramos Santos; Souza; Galvão (1988) quando dizem que o resultado da desqualificação da enfermagem sofre um processo de descaracterização marcado pelo seguinte aspecto: pessoal sem qualificação específica recebe nomenclatura distinta porém a natureza do trabalho permanece a mesma. Assim, surgiram equivalentes do tradicional atendente de enfermagem: auxiliar operacional de serviços diversos, atendente rural, agente de saúde, promotor de saúde e auxiliar de saúde.

Assim, a assistência não qualificada é o produto do trabalho deste servidor que deveria limitar-se a prestar auxilio nas atividades elementares do serviço de enfermagem, que, no entanto, por força de uma gama de motivos como o menor custo salarial, carência de recursos humanos qualificados, se aventura ou é levado a realizar tarefas fora do seu nível de conhecimento expondo a risco a vida de outra pessoa.

\section{METODOLOGIA}

O profissional de enfermagem no exercício de suas atividades deve desenvolver cuidados que visam a manutenção, preservação e restituição da saúde do indivíduo, família e comunidade no âmbito bio-psico-social. Conforme Almeida; Rocha (1989), o processo de trabalho na enfermagem apresenta uma característica básica que é a divisão técnica do trabalho. A prática fragmentada em tarefas, procedimentos e responsabilidades diferentes, cabendo também esta execução parcelada a diferentes agentes e um destes é o atendente de enfermagem. Este fica alienado de todo o processo de trabalho da categoria.

Assim, elaboramos este trabalho de análise qualitativa, pois

"este tipo de pesquisa baseia-se na premissa de que os conhecimentos sobre os indivíduos só são possíveis com a descrição da experiência humana, tal como ela é vivida e tal como ela é definida por seus próprios atores" (Polit; Hungler, 1993: 270).

O presente estudo foi realizado no período de março a julho de 1997 , no município de Fortaleza - Ceará. A população foi composta por profissionais de saúde que lidam/lidaram em seu trabalho com atendentes de enfermagem e a amostra foi formada por 33 profissionais, sendo 12 enfermeiros, 8 médicos, 10 auxiliares e 3 técnicos de enfermagem, lotados em instituições hospitalares públicas e filantrópicas, que foram escolhidos aleatoriamente e se dispuseram a participar do estudo, sendo-lhes garantido o sigilo em relação à sua identificação. 
Os dados foram coletados pelas autoras através de uma entrevista estruturada, que foi gravada para o fiel registro das falas dos sujeitos e durou em média 20 minutos. Os depoimentos foram transcritos e, em seguida, lidos para identificação e delimitação das temáticas. A partir deste momento, analisou-se os depoimentos dos sujeitos, discutindo-os com respaldo na literatura pertinente.

\section{APRESENTAÇÃO, DISCUSSÃO E ANÁLISE DOS DADOS}

Os dados foram agrupados e deram origem às seguintes temáticas: Atuação do atendente no serviço de saúde; Permanência e influência do atendente de enfermagem nos serviços de saúde; Conseqüências do trabalho não qualificado para a sociedade; Profissionalização dos atendentes; Soluções sugeridas para esta problemática.

\section{- ATUAÇÃo do ATENDENTE NO SERVIÇO dE SAÚdE}

Em vista da existência do executor de enfermagem de nível médio há anos, foi legitimado o trabalho realizado pelos auxiliares e técnicos de enfermagem, desenvolvido com atividades que exigem experiência em termos práticos, além de conhecimentos teóricos.

Estando o cliente sob os cuidados de funcionários das instituições de saúde, encontra-se muitas vezes sob assistência de pessoas com conhecimento simplesmente prático, no caso dos atendentes de enfermagem. Esta situação é percebida pelos sujeitos do estudo quando afirmam:

“... Percebo-os fazendo a mesma coisa que um auxiliar de enfermagem, só a remuneração é diferente..." (Enfermeiro)

“... Com relação à atividade prática entre eles, o auxiliar ou o técnico de enfermagem praticamente não tem muita diferença..." (Médico)

“... Pouca diferença da atuação do auxiliar. Não acho que tenham a técnica, mas ninguém trabalha mesmo com a técnica, eu fui atendente por 20 anos." (Auxiliar de Enfermagem)

Apesar de não ser respaldado e fiscalizado pelo COFEN/CORENs, tem-se delimitado, na Legislação de Enfermagem, as funções pertinentes do atendente de enfermagem: atividades elementares como, por exemplo, auxílio na deambulação e higienização. Porém, podemos vê-los nas instituições de saúde em atividades pertinentes ao auxiliar e técnico de enfermagem.

Percebemos, através dos depoimentos, que existe uma grande valorização da destreza manual de detrimento do conhecimento teórico nas ações de saúde pelos próprios profissionais. Porém, percebe-se que, na prática, os profissionais que lidam com o atendente de enfermagem, observam e relatam que este servidor exerce empiricamente atividades as mais diversas, mesmo que estas exijam bom respaldo teórico-prático para a sua realização consciente e eficiente. Estas observações se revelam nos depoimentos seguintes: 
“... Ele simplesmente faz e não sabe as conseqüências do que aquilo pode levar. “ (Enfermeiro)

“... Embora a gente saiba que $o$ atendente é para conduzir o paciente, para dar banho, auxiliar em alguma coisa, (...) eu não vejo nada que você faça no cuidado com o paciente que não tenha que ter a noção da questão científica..." (Enfermeiro)

Estes depoimentos dão ênfase à gravidade que a falta de conhecimento pode acarretar no cuidado prestado ao paciente. Segundo Christófaro (1994: 5),

“... grande parte dos serviços que são realizados nos sistemas de saúde está sob a responsabilidade de trabalhadores que não foram preparados e que não estão qualificados para a especificidade técnica exigida pelo trabalho que fazem. Para a maioria da sociedade, para os usuários em geral, a afirmativa de que grande parte dos serviços de saúde está a cargo destes trabalhadores, pode parecer um falseamento da realidade, mesmo porque, o fato da assistência à saúde estar sendo majoritariamente realizado por não profissionais não é clara e amplamente explicitada para os usuários dos serviços."

Lidar com vidas humanas exige dos profissionais não só conhecimento teórico-prático, mas a consciência da responsabilidade com a qualidade de vida do outro ser humano.

Este envolvimento de profissionais não-qualificados em atividades de maior complexidade nos serviços de saúde está atrelado a diversos fatores como: poucos recursos de nível superior e médio para o exercício legal da profissão, minimização de custos, dentre outros determinantes, gerando assim maiores lucros para os empregadores, mas infelizmente menor qualidade para os usuários e menor reconhecimento para os profissionais responsáveis.

\section{- PERMANÊNCIA E INFLUÊNCIA DO ATENDENTE NOS SERVIÇOS DE SAÚDE}

A permanência dos atendentes de enfermagem no mercado de trabalho influencia a qualidade dos diversos serviços de saúde. Para tanto, durante a entrevista, os sujeitos foram inquiridos sobre como percebiam a permanência dos atendentes de enfermagem nos serviços de saúde.

Assim, alguns profissionais consideraram a permanência dos atendentes de enfermagem como oportuna, visto que eles têm experiência prática. As falas a seguir mostram isso:

“Eles trabalham divinamente bem. " (Auxiliar de Enfermagem)

“ Acho que o atendente tem um papel importante por conta da carência do nosso povo e por conta da falta de profissional de nível médio, principalmente no interior do Estado. " (Médico) 
"Acho que o atendente já faz parte dos serviços de saúde, ele tem muita experiência." (Técnico de Enfermagem)

Através destes depoimentos, percebe-se que os profissionais dão importância ao atendente de enfermagem quando associam as carências do Setor Saúde aos problemas sócio-políticos e econômicos. Portanto, colocam a habilidade prática como fator de relevância. De acordo com Almeida; Rocha (1989: 71), " o primeiro agente da enfermagem a ser institucionalizado foi o atendente." Talvez por isso os profissionais julgam importante a experiência daqueles, visto que a prática que foi adquirida no decorrer da atuação em serviço e a carência de profissional habilitado ainda deixa um espaço para atuar.

Dos entrevistados, alguns referiram-se ao aspecto negativo da permanência e influência do atendente de enfermagem. As falas seguintes referem-se a isto:

" Eu acho que a falta de preparo, de conhecimento científico (..) repercute na imagem da enfermagem. Além disso, por aprenderem só por prática, quando tem inovação em qualquer coisa, é a maior dificuldade para eles acertarem." (Enfermeiro)

“ Os atendentes não têm formação, os mais velhos têm experiência, mas é só prática e não sabem o porquê de cada coisa que faz." (Técnico de Enfermagem)

"Eles não trabalham com técnica e é ruim ter que ensinar tudo." (Médico)

Assim, os entrevistados referem-se acerca das dificuldades em trabalhar com os atendentes de enfermagem pelas limitações de aprendizagem que eles apresentam, em muitas situações, pelo desinteresse em reciclar seus conhecimentos. Nogueira, citado por Castro (1988), lembra que o sistema atribui aos atendentes de enfermagem uma quantidade expressiva de funções, umas realmente simples, mas outras requerem conhecimento e senso crítico. Porém, eles não têm preparo adequado, seja no tocante aos aspectos da educação geral, seja na capacitação propriamente profissionalizante.

\section{-CONSEQÜÊNCIAS DO TRABALHO NÃO QUALIFICADO PARA A SOCIEDADE}

Sendo o trabalho em saúde exigente de habilidades manuais e intelectuais, exige, também, de seus profissionais a responsabilidade legal pela qualidade final de seu produto. Quando os executores do cuidado ao ser humano não preenchem os requisitos do saber e do fazer, ou seja, o conhecimento da teoria e da prática, as conseqüências são sofridas pelo usuário deste serviço e podem, até mesmo, ser letais.

A sociedade paga impostos, os quais devem ser usados em seu favor. Quanto ao Setor Saúde, as pessoas confiam os seus corpos aos cuidados dos profissionais daquela instituição, esperando destes um trabalho seguro embasado em saber teórico-prático. Porém, muitas vezes, elas não recebem exatamente o cuidado pelo qual pagaram, obtendo-o de pessoas que, na verdade, não tiveram qualificação adequada, tendo como exemplo os atendentes de enfermagem. 
A dificuldade de qualificação também é um fator agravante, visto que os empregadores não propiciam o acesso do atendente de enfermagem ao curso profissionalizante.

Por tudo isto, a imagem da assistência de enfermagem foi prejudicada devido à presença de trabalhadores não-qualificados que oferecem à sociedade cuidados sem respaldo teórico-prático. De acordo com Castro (1988: 187), " a face do problema que geralmente é percebida pelos consumidores dos serviços de enfermagem é que os padrões assistenciais são insatisfatórios em quantidade e qualidade."

Estas idéias são apropriadamente evidenciadas nos depoimentos dos seguintes sujeitos:

“... Atendentes não têm nenhuma formação, (...) a população que está sendo atendida é posta em risco... " (Enfermeira)

“ A sociedade vê que não está tendo aquilo por que ela pagou, (...) está com uma pessoa que só tem a prática, não tem teoria..." (Auxiliar de Enfermagem)

“... A sociedade paga o preço, (...) vai receber um serviço com qualificação abaixo do que ela merece... " (Médico)

Ou seja, a sociedade sofre as conseqüências ao pagar e usar um serviço prestado por um trabalhador sem habilitação teórico-prática e legal podendo pôr em risco vidas humanas.

Ainda, como veremos no depoimento a seguir, a sociedade não possui conhecimento da categoria do trabalhador do serviço em saúde por ela utilizado:

“... As pessoas vão ao hospital pensando que vão ter uma melhor qualidade de trabalho e, chegando lá, nem sabem que estão sendo atendidos por pessoas que não têm qualificação..." (Enfermeira)

Isto mostra o quão desatencioso está o brasileiro quanto à qualidade do produto por ele consumido. Em questão de saúde, portanto, é um problema extremamente sério que pode interferir na sua qualidade de vida ou, até mesmo, pôr em risco sua condição de sobrevivência.

A continuação do atendimento de enfermagem no serviço de saúde por pessoal não qualificado se identifica exatamente com este problema, ou seja, com a falta de preparo prático respaldado no teórico.

A sociedade continua servindo-se de cuidados sem qualidade. Isto repercute na imagem dos verdadeiros profissionais da saúde, principalmente os de enfermagem, que são facilmente confundidos pela população não só com atendentes, mas com os demais executores do serviço elementar da profissão. 


\section{- PROFISSIONALIZAÇÃO DOS ATENDENTES}

A Lei 7.498/86, sancionada pelo então Presidente da República, José Sarney, bem como a Resolução COFEN 111/89, limitavam a presença de trabalhadores sem formação específica na enfermagem como executores de atividades elementares até 1996. Com isso, evidenciou-se uma tentativa de profissionalização dos recursos humanos sem qualificação, os atendentes de enfermagem.

A suplência profissional constituiu-se em uma estratégia para esta profissionalização, que se realiza através de provas de conhecimentos específicos aplicadas aos atendentes de enfermagem que comprovem a prática por um período mínimo de dois anos. Estas provas avaliam os conhecimentos teóricos e práticos. Se aprovados, os atendentes que têm a escolaridade exigida passam a ter título de auxiliar de enfermagem. Outra tentativa de profissionalização dos atendentes de enfermagem surgiu nas próprias instituições de saúde que criaram cursos de auxiliar e/ou técnico de enfermagem para que seus atendentes pudessem trabalhar com mais qualidade.

Indagou-se, então, aos sujeitos entrevistados sobre sua opinião quanto à profissionalização deste trabalhador; os seus depoimentos representam o que eles pensam:

" Acho que através da profissionalização tudo vai melhorar, o serviço vai ter mais mão-de-obra com conhecimentos." (Técnico de Enfermagem)

“A profissionalização é uma forma de aperfeiçoar o atendente, descobrir o conhecimento, através dos estudos e de treinamentos." (Enfermeiro)

“É bom porque fazer curso dá para se adaptar mais ao trabalho e de vez em quando têm congressos e seminários para gente que é auxiliar, já para o atendente não tem." (Auxiliar de Enfermagem)

“Eu percebo a profissionalização como uma necessidade, pois dentro da realidade em que $o$ atendente é exposto ele faz mais do que é capaz, então ele tem que se profissionalizar." (Médico)

Através dos depoimentos referidos pode-se notar que os profissionais entrevistados apoiam a profissionalização, consideram que a assistência pode melhorar, visto o aprimoramento do trabalhador. De acordo com Capella et al. (1988: 167), " a profissionalização além de garantir conhecimentos técnicos necessários ao exercício da profissão, oportuniza melhores salários devido a qualificação, bem como, refletirá na qualidade da assistência prestada."

Alguns dos entrevistados se mostraram contra o processo da profissionalização, principalmente em relação ao modo como vem ocorrendo. Os depoimentos a seguir confirmam isto:

"Sou terminantemente contra esta profissionalização, acho que não deveria Ter atendente e profissionalizá-los não adianta muito, porque o processo em que está ocorrendo não é bom." (Enfermeira) 
“ Não concordo com a profissionalização, principalmente com o jeito que estão fazendo, muitas vezes $o$ atendente passa a ser auxiliar mas não muda a sua postura, então não adianta. " (Enfermeira)

“ Não considero que essa profissionalização tenha sido feita de uma maneira pelo menos eficaz, não por culpa dos atendentes mas devido à conjuntura. $A$ instituição pressiona para que o atendente se profissionalize, mas não dá condições para uma boa profissionalização e ele não tem condições de financiar uma profissionalização de qualidade. " (Médico)

Através destes depoimentos pode-se entender que estes entrevistados se mostram contra o processo em que vem sendo feita a profissionalização. Segundo Santos; Souza; Galvāo (1988: 78):

“ As instituições escolares que oferecem ensino regular profissionalizante não apresentam em geral condições de ensino adequadas, há insuficiência de docentes, campo de prática e material didático. A alternativa do ensino supletivo via exame de suplência profissionalizante têm demonstrado na prática dois problemas: o primeiro refere-se ao baixo índice de aprovação nos exames em decorrência das características do exame, e da falta de preparo científico. Segundo, aqueles que logram aprovação, não apresentam na prática, nenhuma alteração em sua performance, estando portanto habilitados, mas não qualificados. Além disso, o trabalhador têm que financiar, à custa de seus baixos salários os cursos preparatórios altamente questionáveis, para o exame."

Assim, pode-se afirmar que o processo de profissionalização dos atendentes de enfermagem se faz necessário, de modo que favoreça o aprendizado de conhecimentos teórico-práticos, mas é importante haver definição de estratégias que permitam um processo válido e possam ser implementadas através do envolvimento dos serviços e profissionais da saúde, bem como da sociedade em geral.

\section{- SOLUÇÕES SUGERIDAS PARA ESTA PROBLEMÁTICA}

A questão histórica da gradual inserção de trabalhadores não qualificado nos serviços de saúde evidencia-se hoje com um leque de novas ocupações que foram surgindo. Principalmente devido aos problemas financeiros, esses trabalhadores sem preparo teórico-científico responsabilizam-se por atividades consideradas corriqueiras, como conduzir um paciente ao banho, auxiliar na deambulação, entre outras atividades. Porém, eles foram induzidos pela conjuntura a assumirem paulatinamente outras práticas que, na verdade, exigem alta qualificação como procedimentos invasivos, administração de drogas, entre outros.

Instigando os profissionais de saúde que trabalham com atendentes de enfermagem a refletirem sobre a situação do serviço de saúde, obtivemos as seguintes opiniões: 
“... separar os atendentes do resto do grupo de enfermagem, (...) separá-lo do COREN, (...) separá-lo da área de saúde porque ele é um funcionário de serviços gerais. (..) Ele devia ter outro nome..." (Enfermeira)

“ Acabar a questão da hierarquia, o corpo da enfermagem tem que ser pensado como um só. (...) Abolir com a questão do atendente..." (Enfermeira)

Estas falas revelam a necessidade dos sujeitos em tornar a enfermagem forte através da separação do profissional não qualificado do restante da equipe de enfermagem, sugerindo que $o$ fato de existir atendentes de enfermagem diminui o reconhecimento da profissão, mas entende-se que isto não se constitui em impasse para o crescimento da profissão.

Outros entrevistados referem que a escolarização desse pessoal é uma saída mais fácil para esta problemática, como se percebe nestas falas:

“ Dentro do próprio hospital deve haver cursos, mas não só de profissionalização, mas também de variedades e novidades na saúde..." (Enfermeira)

“Deve começar a fazer o curso de auxiliar de enfermagem em vários locais, para eles estudarem a teoria." (Auxiliar de Enfermagem)

“... As representações de classe da categoria de enfermagem deviam assumir essa luta da profissionalização do atendente. (...) É muito mais fácil torná-lo um bom auxiliar de enfermagem do que pegar uma pessoa que nunca freqüentou um hospital... " (Médico)

Estes sujeitos revelam o desejo de aproveitar a experiência do atendente na assistência hospitalar porque consideram que esse ocupacional não exerce somente aquelas atividades que lhe cabem, pois, muitas vezes, atuam como um profissional de nível médio, sem subsídios teóricos que exigem estas atividades. Sendo assim, afirmam que as habilidades exercidas atualmente sem capacitação devem ser aprimoradas de maneira a embasar o fazer deste trabalhador. Porém, os vícios adquiridos durante todo o tempo em que atuou sem qualificação legal parecem não ser corrigidos apenas com um curso de auxiliar de enfermagem, até porque isto está relacionado a uma questão de consciência pessoal e profissional.

Talvez esta falta de interesse pela profissionalização esteja atrelada a uma didática inadequada para este tipo de aluno, em sua maioria mulheres casadas, de idade mais avançada e com filhos, ou com interesses voltados apenas para a prática sendo desvalorizada a teoria; mas acredita-se que, se tais cursos tivessem mais atrativos, como aulas bem dinâmicas, por exemplo, as pessoas poderiam se sentir mais motivadas a participar e a frequentá-los com mais interesse.

E o que encontramos nas instituições de saúde, em sua maioria, é o que os entrevistados depõem a seguir: 
“... Eu ainda trabalhei dois anos como atendente. (...) Não senti nenhuma diferença no trabalho, só no salário que é um pouquinho a mais ..." (Auxiliar de Enfermagem)

“... Deveria haver uma reciclagem, e não um curso para ver tudo de novo." (Auxiliar de Enfermagem)

“... Ele não sabe o valor do curso de auxiliar. O interesse maior dele é a promoção funcional e ganhar dinheiro, mas nunca pensam na melhoria da qualidade do seu trabalho..." (Enfermeira)

Com isso, nota-se a pouca importância dada à teoria, ao embasamento científico, superestimando a prática pela prática. Porém, buscar obter um aperfeiçoamento na área de interesse implica na aquisição de uma ampla gama de conhecimentos, que melhor respaldará a prática ao invés de subestimá-la, constituindo-se assim um verdadeiro aliado no desenvolvimento da mesma.

Os atendentes, auxiliares e técnicos de enfermagem parecem revelar descrédito na valorização da ampliação do conhecimento científico e valorizam mais a destreza manual, o que, infelizmente, torna a enfermagem uma profissão culturalmente vista como tarefeira.

Outro indivíduo sugeriu ainda:

“... acho que deveria existir uma definição para o atendente de enfermagem, definindo exatamente qual o seu papel... “ (Médico)

Este depoimento mostra a preocupação do profissional de saúde em aproveitar a experiência do atendente de enfermagem e definir seus papéis. Mas este trabalhador já tem suas funções delimitadas na Lei 7.498/86 e discriminadas na Resolução COFEN - 186, de 1995, constante na Legislação do COREN (1997: 40); são elas:

“... ações de fácil execução e entendimento, baseadas em saberes simples, sem requererem conhecimento científico, adquiridas por meio de treinamento e/ou prática; requerem destreza manual, se restringem a situações de rotina e de repetição, não envolvem cuidados direitos ao paciente, não colocam em risco a comunidade, $o$ ambiente e/ou a saúde do executante, mas contribuem para que a assistência de enfermagem seja mais eficiente "

Ou seja, são apenas as atividades relacionadas com higiene, conforto e transporte do cliente, com a organização do ambiente, com consultas, exames, tratamentos e com a preparação do corpo após óbito.

Entretanto, por mais claras e limitadas que sejam suas atividades, o atendente de enfermagem é visto pelos profissionais da saúde como ocupacional sem função definida, talvez pelo desconhecimento da Legislação de Enfermagem ou mesmo porque as pessoas tomam por base o que vêem na prática dos serviços de saúde. 


\section{CONSIDERAÇÕES FINAIS}

Através da elaboração do presente estudo, pôde-se compreender a questão do atendente de enfermagem como uma problemática ética, política e social por estar relacionada a fatores envolvidos no cuidar, visto que estes trabalhadores não receberam preparo formal em teoria e prática.

Isto aponta para uma polêmica entre os profissionais de saúde, pois alguns destes mostraram-se a favor da permanência dos atendentes de enfermagem nos serviços de saúde, devido à sua experiência prática. Outros apresentam-se contra considerando o comprometimento da assistência, a insuficiência dos conhecimentos teórico-práticos como condição básica para o exercício de uma enfermagem de excelência.

Considera-se que a problemática é complexa e exige uma discussão ampla no sentido de melhoria da qualidade dos serviços de saúde, assim como a necessidade dos profissionais conscientizarem-se que esta questão é séria, mas que não é o único motivo dos problemas da área.

Quanto à profissionalização do atendente de enfermagem, comungamos com Vieira (1992: 15) quando diz que:

"A qualificação profissional na enfermagem vem sendo objeto de preocupação há décadas, sem que entretanto a questão dos atendentes e similares fosse contemplada na sua devida importância. Embora tenha surgido em vários momentos manifestações e implementação de programas de qualificação, eles se diluiram diante do crescimento desordenado dos atendentes comandados pelo mercado de trabalho."

Deste modo, vemos que é mister a qualificação profissional para os atendentes de enfermagem, mas entendemos que se faz necessário uma política definidora de estratégias para que o processo seja eficiente, de modo que envolva e estimule efetivamente 0 atendente. Assim, consideramos importante o envolvimento dos profissionais de saúde, principalmente os que fazem a enfermagem, bem como a sociedade, visto que esta é assistida por tais trabalhadores.

Concluindo, podemos entender que a questão do atendente de enfermagem é muito mais complexa que imaginávamos e ainda temos dúvida como: atendentes de enfermagem: Por quê? Até quàndo?

\section{REFERÊNCIAS BIBLIOGRÁFICAS}

1. ALMEIDA, M. C. P., ROCHA, J. S. Y. O saber de enfermagem e sua dimensão prática. 2. ed. Săo Paulo: Cortez, 1989. 128 p.

2. ANTUNES, M. J. M. Enfermagem como espaço de inserçăo de trabalhadores não-qualificados. Anais do 470 . Congresso Brasileiro de Enfermagem. Goiânia: Ed. da UFG., 1996. 
3. BARROS, S. M. P. F., SILVA, N. F. da, CHRISTÓfaRO, M. A. C. Recursos humanos de saúde: um desafio estratégico para a qualidade de assistência de saúde e para a organização do SUS: com ênfase na Enfermagem. R. Bras. Enferm., Brasília, v. 44, n. 1, p. 7-9, jan./mar. 1991.

4. CAPELLA, B. B., GELBECKE, F. L. Enfermagem: sua prática e organização. R. Bras. Enferm., Brasília, v. 41, n. 2, p. 132-139, abr. jun. 1988.

5. CAPELLA, B. B. et al. Profissionalização da enfermagem: uma necessidade social. R. Bras. Enferm., Brasília, v. 41, n. 2, p. 161-168, abr. jun. 1988.

6. CASTRO, I. B. e. A evolução do setor saúde e a crise da enfermagem brasileira. R. Bras. Enferm., Brasília, v. 41, n. 3 e 4, p. 183-89, jul./dez. 1988.

7. CHIARI, M. L. M. DE. A(o) enfermeira(o) e a enfermagem. $33^{\circ}$. Congresso Brasileiro de Enfermagem. Manaus, Anais. Brasília: ABEn. 1981 p. 4347.

8. CHIZzOTTI, A. Pesquisa em ciências humanas $e$ sociais. 2 ed. São Paulo: Cortez, 1995. 164p.

9. CHRISTÓFARO, M. A. C. Editorial: Sobre a profissionalização de trabalhadores da saúde sem qualificação específica. R. Bras. Enferm., Brasília, v. 47, n. 1, p. 5-6, jan./mar. 1994.

10. CIANCIARULLO, T. I. Editorial: ciência da enfermagem a serviço da comunidade. R. Esc. Enferm. USP., v. 29, n. 1, p. 1-2, abr. 1995.

11. COREN. Legislação. Fortaleza: Minerva, 1997. 42p.

12. LIMA, M. J. de. O que é enfermagem. São Paulo: Brasiliense. 1994. 94p.

13. LORENZETTI, J. Editorial: Legislação adequada para a Enfermagem: uma necessidade a ser conquistada. R. Bras. Enferm., Brasília, v. 40, n. 4, p. 179 , out./dez. 1987.

14. POLIT, D. F., HUNGLER, B. P. Fundamentos de Pesquisa em Enfermagem. 3. ed. Porto Alegre: Artes Médicas, 1995. 391 p.

15. RIBEIRO, C. M. Avaliação da assistência de Enfermagem. $29^{\circ}$. CONGRESSO BRASILEIRO DE ENFERMAGEM. Camboriú, Anais. Brasilia: ABEn. 1977. p. 51-57.

16. SANTOS, I. dos; SOUZA, A. M. de A.; GALVĀO, E. A. Subsídios para formulação de uma política de profissionalização para o pessoal de enfermagem sem qualificação específica. R. Bras. Enferm., Brasília, v. 41, n. 1, p. 75-80, jan./mar. 1988.

17. VIEIRA, A. L. S. Perfil do nível elementar de enfermagem no Estado do Rio de Janeiro: caracterização da demanda para a profissão. R. Bras. Enferm., Brasília, v. 45,n. 1, p. 15-20, jan./mar. 1992. 